\title{
Judgments Based on the Recognized Offense in Accordance with the Jordanian Jurisdiction Law: A Comparative Study
}

\author{
Zaid Ibrahim Yousef Gharaibeh ${ }^{1}$ \\ ${ }^{1}$ Ajloun National University, Jordan \\ Correspondence: Zaid Ibrahim Yousef Gharaibeh, Ajloun National University, Jordan. E-mail: \\ gharaibeh.zaid@yahoo.com
}

Received: January 5, 2019

Accepted: January 25, 2019 Online Published: February 16, 2019

doi:10.5539/jpl.v12n1p32

URL: https://doi.org/10.5539/jpl.v12n1p32

\begin{abstract}
The Jordanian legislator amended the text of Article 31 of the Code of Criminal Procedure by amendment of Law No. 32 of the year 2017.

Where the legislator was in favor of this amendment, where the second paragraph of the text of the amended article which states (and whoever violates this prohibition is arrested, he is then referred to the magistrate for trial).

If the amendment is found to be contrary to the judicial officer, is transferred to the magistrate, While the legislator in accordance with the old text gives the prosecutor the right to arrest, which is sometimes arbitrary, and waste the rights of individuals and deprive them of their freedoms, if the Jordanian legislator by amending this text is successful, to protect freedom from aggression.
\end{abstract}

Keywords: recognized offense, Jordanian Jurisdiction Law, criminal procedure

\section{Introduction}

The criminal offense is considered one of the most serious crimes that concern the society, the security apparatuses and the competent judicial authorities, in view of what is left in the hearts from deep impact, the legislation provided special and exceptional measures that impede the speed of movement to reach optimal results by arresting the perpetrator before leaving the scene of the crime, and before he can get rid of his crime and impunity, and in order to reach evidence before its disappearance and disintegration, and hearing witnesses before forgetting or influencing them to prevent them from reporting what they saw, things will become more complicated and it will be difficult to detect the crime and the perpetrator.

Therefore, most legislations seek to identify the procedures and actions that the justice officer can take in such cases. This is considered from a type of development of legislative progress, which is always aimed at protecting communities and providing security to citizens.

The Jordanian legislator is going on in full swing in achieving the desired objectives of the Penal Code, as well as the Code of Criminal Procedure. To facilitate the work of the justice officers and protect the rights of citizens which was guaranteed by the Jordanian Constitution, and to bring the perpetrators of crimes to justice, and judiciary to reduce these phenomena that the make citizens feel insecurity, therefore, the legislator has taken a sound approach in cases of recognizable offense.

\subsection{Problem of the Study}

The fact that the criminal justice function is limited to carrying out the preliminary research work in the investigation of crimes and the collection of evidence does not include directly the investigative work of the investigating authority. However, the occurrence of the crime at the sight of the officer of the judicial police, or detecting it after the occurrence of a short time and its evidence is visible to justify the departure from the general rules in the Code of Criminal Procedure Law grant this officer a degree of investigative authority to enable him to intervene immediately and quickly to control the evidence before it is lost, obliterated or misrepresented, and the situation does not fear such violation of individual freedoms and rights as long as the evidence is clear and visible so that it decreases or to avoid the possibility of error in appreciation or rush in the accusation to the defendant. 
The problem of the study seems to us in examining the paradox between the Jordanian and Iraqi laws in this regard, in addition to the lack of clarity on the scope of the expansion of the powers of the judicial police to infringe upon the freedoms of persons before they are convicted by a court order in both laws. On the other hand, the second problem is the paradoxes between both the Jordanian and the Iraqi laws in defining the framework of the exception and prohibit some of the acts assigned to the original investigative authority by the legislator.

\subsection{Importance of the Study}

The importance of the study is illustrated by the knowledge of the concept of the recognized offense, its cases and conditions, and the importance of the amendment contained in the texts of the criminal of recognized offense in the Criminal Procedure Law No. 32 of the year 2017.

\section{The Offense, Its Circumstances and Conditions}

We will discuss in this subject the clarification of the concept of the recognized offense, its circumstances and conditions, and be the first requirement for the definition of the recognized offense, and the second we will talk about the cases of the recognized offense, and the third requirement and the conditions of recognized offense.

\subsection{Definition of the Recognized Offense}

The seizure of the crime in the case of being caught out, justifies on going out on the general rules in criminal proceedings, by speeding up the procedures for fear of loss of evidence, when the error is in the estimation or maliciousness of the accused is either negligible or probability of weakness. And then make the law "Red-handed" special provisions, including the authorization of the judicial control officer the power of verification is within limits.

Some Arab legislation has inquired the term "recognized offense" and other legislations used the term "Red-handed" means the actual scenes of the crime. It means a period of time from the moment of committing the crime to its discovery, the meaning of "“Red-handed" " in the Latin system is different from the Anglo-American system. Where the Latin system is considered "Red-handed" is a description of the crime itself, either the American system describes the offender and some Arab laws that were taken with this system, such as Sudan, it provided a textual translation of these laws, where we find in the Sudanese law taken from the laws of Anglo-American, a phrase the words in his presence that changes the recognized offense from the description of the crime to the description of the offender and add them to this expression phrase and added to this phrase the

expression " Found committed " in the Anglo-American system so as to infringe on the freedoms of individuals granted by the Constitution to them violated, and the actual commission must be observed or practiced during the commission of the criminal offense ${ }^{(1)}$.

The jurists of Latin law know that the recognized offense is a case that does not fall into the composition of the crime, but is related to its discovery, because it includes the crime without its action and is achieved by seeing them when they occur or after a short time, the actual viewing of the crime and not for the perpetrator, the little time between their commission and their discovery is the basis of the case to the recognized offense ${ }^{(2)}$,

Which is defined by the Jordanian law in the text of Article 28 of the first paragraph, that the recognized offense is the offense witnessed by the state of commission or the completion of the commission ${ }^{(3)}$. Which was taken by the Syrian legislator in Article 25 of the Code of Criminal Procedure and the Lebanese legislator in the text of Article 36 of the Lebanese Code of Criminal Procedure?

According to the French Penal Code, the recognized offense does not exceed more than 24 hours from the moment of the commission of the offense, as Article 53P2 stated, as well as the right of the French legislator to the case of the recognized offense committed in a house, and even if it was not remarkable though it was not memorable but at the request of the owner of the house from the officer or the Attorney General interference and the seizure of the offense, then he is considered a criminal suspect in the recognized offense, the proceedings are carried out as a recognizable offense, this situation is often applied to crimes discovered by the owner after a long absence from his home, such as the discovery of a stolen summer house.

And in the definition of the Egyptian judiciary about the recognized offense he defined it as a state of the crime

\footnotetext{
${ }^{1}$ Al-Jabour, Dr. Mohamed Odeh, Jurisdiction of the Disciplinary Officer is a Comparative Study, First Edition, Arabic House of Encyclopedias. 1986, page224.

${ }^{2}$ Al-Bahar, Dr. Mamdouh Khalil, Principles of Jordanian Criminal Procedure Law, House of Culture for Publishing and Distribution 1998, p. 206.

${ }^{3}$ Jordan Criminal Procedure Law No. 9 of the year 1961 and its amendments.
} 
itself, not a perpetrator ${ }^{(4)}$.

Patterns of "Red-handed" are thus the actual viewing of the crime or the time-lapse between its detection and its occurrence.

One of the characteristics of "Red-handed" that emerges from the previous definitions of "Red-handed" according to the Latin system is:

- It is an in-kind case associated with the crime itself, and not to the person who committed the crime, in the sense that it is not necessary to see the perpetrator at the time of the crime.

- "Red-handed" depends on external appearances by observing the physical element of the crime at the time of its occurrence or to see what it reveals a moment ago, The judicial commissioner himself sees these external appearances because he is the one authorized by law to carry out the necessary procedures for the case of "Red-handed" in which the men of the judicial authority are released on the general rules with the extraordinary special powers granted to him by the Code of Criminal Procedure ${ }^{(5)}$.

\subsection{Cases of Recognized Offense}

Jurists in various legislation sees cases in which the offender is "Red-handed" in the recognized offense are:

\subsubsection{Watch the Crime When Committed}

It is the one who sees the case committed by the offender and surprises him with the witnesses or the men of authority while committing the crime.

\subsubsection{Watching the Crime Shortly after It Was Committed}

This situation differs from its predecessors because the commanding officer did not witness the physical acts of the crime but rather witnessed what was committed in the place of the attack as he saw the victim and blood bleeding from his body.

\subsubsection{Trace the Perpetrator Following the Crime}

Which is known as the case of prosecution and the prosecution is immediate and not separated long between the commission of the crime of prosecution and most of the prosecution may be just hearing the scream of the victim.

\subsubsection{Watch the Evidence of the Crime}

Is to see the perpetrator who owns or carries the tools of crime did not specify the legislator the period of time to consider in such situation of "Red-handed" but rather leaves it to the discretion of the judiciary as did the French and Egyptian penal legislators ${ }^{(6)}$.

\subsubsection{The Perpetrator Was Arrested on the Basis of People Screaming after the Incident}

Where this case is achieved by arresting the perpetrator as the victim follows the offender or is followed by people with a scream after the crime.

\subsubsection{If You Find the Complainant at the Time Mentioned the Effects and Signs of Doing So}

It may be that the complainant has traces or signs such as scratches as a result of resistance or wounds or displacement from climbing or bloody spots that may be have this effect in the proof, because the presence of traces or signs of the complainants at least the condition of having things or the holder of the arms or papers indicating the commission of the crime ${ }^{(7)}$.

The legislator Jordanian penal cases of "Red-handed" In the partial law in article 28 of the first and second paragraphs of five cases, namely:

A) Watch the offense if committed.

B) Watch the offense when the offense is over.

\footnotetext{
${ }^{4}$ Master Theses of the researcher: Bilal Mahmoud Al-Murhej Al-Haiti, The suspicious crime and the effects of the expansion of the judicial control authority comparative study of Jordanian and Iraqi, published in Middle East University, 2010/2011, p15.

${ }^{5}$ Najem,Dr. Mohammad Sobhi, The brief in the Code of Criminal Procedure, Third Edition, House of Culture for Publishing and Distribution, 2016, p 212.

${ }^{6}$ A previous reference to Dr. Mohamed Odeh Al-Jabour, page 232.

${ }^{7}$ Al-Hadithi, Dr. Fakhri Abdul Razzaq, Explanation of the Code of Criminal Procedure, Dar Al Thaqafa for Publishing and Distribution, First Edition, Amman / Jordan 2011, pp. 201-200.
} 
C) The arrest of the perpetrator on the basis of people screaming after the occurrence.

(D) The perpetrator of the crime and possession of objects, weapons or papers, which indicates that he is the perpetrator of the offense, within twenty-four hours of the offense.

(E) If the accused appears after the crime and traces indicate that he is the perpetrator of the crime ${ }^{(8)}$.

\subsection{Conditions Recognized Offense}

It is necessary to have "Red-handed" the legal effects are that there are several conditions the authorities of the judicial authority shall be able to take proper investigative measures such as the arrest and inspection of persons, houses and conditions that are required are:

\subsection{1 "Red-handed" Prior to Interrogation Actions}

"Red-handed" must be detected prior to any of the investigation procedures carried out by the member of the judicial officer without the permission of the investigating authority. This means that the "Red-handed" is proved to be the right of the member of the judicial police to arrest the suspect or search him or search his house and adjusts things.

\subsubsection{Detecting the "Red-handed" in a Lawful Way}

"Red-handed" must be detected following the path of a legal way that does not violate the law, which entails that the case of "Red-handed", it is not considered fit, if you see a member of the judicial police have been achieved by illegal means, the presence of a member of the criminal justice system is not considered valid for the crime committed inside the house by entering the house illegally, it does not have the "Red-handed" if it is a result of views in a manner that is contrary to public morals, or the inviolability of dwellings, such as looking through holes and doors.

2.3.3 "Red-handed" Must Be Detected by the Member of the Judicial Officer Who Has Taken the Verification Procedure of "Red-handed" by Himself

The case of "Red-handed" should be discovered by the member of the forensic officer who has taken the verification procedure himself, it is not enough to get the news through the novel version from who saw it, when he has not been witnessed by the cases of "Red-handed", and that it is not required to see the member of the criminal officer during, during the commission of the crime, but it is sufficient to attend the place of occurrence after the commission of the crime ${ }^{(9)}$.

\section{Acts That the Prosecutor May Take in the Recognized Offense and the House}

Having clarified the concept, circumstances and conditions of the "Red-handed", we shall discuss in this modern research in the first requirement on the transfer of the prosecutor or members of the judicial police to the place of the incident, and the second request to prevent attendees to move away from the scene of the crime.

\subsection{Move to the Premises}

The Jordanian Penal Code of Criminal Procedure states in Article 29 of the first paragraph that (if a "Red-handed" crime is committed that requires a criminal penalty, the Prosecutor must immediately move on to the crime scene), and that the Prosecutor or the members of the judicial officer are charged with investigating crimes, collecting evidence and arresting their perpetrators? The law requires the officers of the judicial police to immediately inform the public prosecutor if they are aware of the occurrence of a serious offense and carry out his instructions regarding legal proceedings, and where article 21 of the penal code and article 44 of the Code of Criminal Procedure the members of the judicial police shall promptly submit to the Prosecutor without delay the information concerning the crimes committed in the places where the exercise of their functions and to inform the Prosecutor immediately the "Red-handed" crimes of the time, and to deposit with him without delay the minutes of seizure they organize in the cases authorized for them with the rest of the papers, articles 44 and 49 of the said Act are no doubt binding by the members of the judicial police in these proceedings.

To enable the Prosecutor to initiate the investigation, in the interest of this, that the members of the judicial police and the delay in the response does not call for the nullification of the measures that will be taken later, the law did not recognize the affirmative action as a procedural penalty and therefore the delay of the member of the judicial control in moving to the premises in the case of "Red-handed" to perform the duties mentioned therein

\footnotetext{
${ }^{8}$ A previous reference to Dr. Mamdouh Al Bahar, p. 207.

${ }^{9}$ A previous reference to, Dr. Fakhri Al-Hadithi p. 203-202
} 
shall not result in invalidity, but shall expose him to punitive and other punishments ${ }^{(10)}$. In accordance with article 22 of the Code of Criminal Procedure of Jordan, stipulates that if the officers of the judicial police are limited to the tasks entrusted to them, the prosecutor shall organize the investigation into the case and submit it to the Attorney General, who shall refer it to the competent prosecutor or the competent court, as appropriate, to perform the legal requirement ${ }^{(11)}$.

\subsection{To Prevent Audience to Move away from the Scene of the Crime}

The legislator has authorized a member of the judicial police when he is transferred in the case of the "Red-handed" crime, to prevent any person who is present in the house or in the place where the crime took place to leave it or to move away from it, this prohibition continues until the record is released and the status of the place is confirmed and crime scene and the persons, and when the investigator conducting the investigation completes the organization of the minutes, lift the ban on people.

This prohibition is an organizational procedure so that the judicial officer can prepare and organize of the minutes record, anyone who contravenes these orders is placed in the place of detention to attend the magistrate's court to be tried and sentenced after hearing his words ${ }^{(12)}$.

However, the Jordanian legislator amended the text of Article (31) as stated in the first paragraph of Article (31) of the Jordanian Partial Procedure Law stating that (the Attorney General shall prevent any person who is present in the house or the place where the crime took place from leaving it or going away from it until the of the minutes of record is released), preventing those present from leaving the place of the incident or withdrawing from it, is an organizational procedure intended to allow the judicial officer to perform his mission within conditions of the system in the place of the incident, and make use of the information available to them, which may be the original perpetrators of the crime or its partners and to avoid any tampering or distortion of evidence

The purpose of the crime is to allow the judicial authorities to perform their mission within conditions of the regime at the scene of the incident and to make use of the information available to them, which may be the original perpetrators or accomplices of the crime, and to avoid any misrepresentation or distortion of evidence of the crime, where this measure is not a detention to the persons or arrest them, it is also intended to provide the officer with the opportunity to carry out his mission by avoiding tampering with or distorting the evidence of the crime, these procedures do not involve any exposure to freedom, the public interest is above the private interest.

The Egyptian legislator who followed this approach was influenced by the French legislator, where the Egyptian legislator cited the impact of Article 32 of the Code of Criminal Procedure of Egypt as (for the judicial control officer when he is in the act of the "Red-handed" crimes may prevent those present from leaving the place of the incident or withdrawing from it until the minutes record is released, and he may immediately summon those who can obtain clarifications regarding the incident).

The researcher considers that the Jordanian legislator in modifying the second, third, fourth and fifth paragraphs of article 31 of the Penal Procedures Law in the amendment of Law No. 32 of the year 2017 the amendment was so successful where Paragraph 2 of the text of the amended article states that (And whoever violates this prohibition is arrested and then referred to the magistrate for trial), as the amendment is contained in a violation of the officer of the judicial officer is transferred to the magistrate judge, while the legislator according to the old text gives the prosecutor the right to arrest, which is arbitrary sometimes and waste the

rights of the people and deprive them of their freedoms, and the Iraqi legislator did not grant such authority to the Prosecutor where the Iraqi legislator was granted the power to codify the minutes of record by abstaining and not complying with the orders of the judicial officer, as stipulated in Article 44 of the Iraqi Code of Trials (....and if one of these things is violated they will write it down in the minutes record).

The third paragraph of Article 31, as amended by the amendment in Law No. 32 of the year 2017, stipulates that (he may immediately bring in every person who can obtain clarifications about the crime, and if one of the decisions of the Prosecutor contravenes this matter, this shall be recorded in the minutes record), we believe that the legislator of this amendment explicitly approaches the approach of the Iraqi legislator who preceded and that we talked about in the article 44 of the Iraqi Criminal Procedure Code, where the old text in the absence of attendance to judge that person in absentia, and this amendment restricts the authority of the judicial police

\footnotetext{
${ }^{10}$ A previous reference to, Dr. Fakhri Al-Hadithi p. 205-204

${ }^{11}$ The Criminal Procedure Law No. 9 of 1961 and its amendments

${ }^{12}$ Namour, Mohammad Said (2016), Principles of Criminal Procedures Explanation of the Code of Criminal Procedure, Fourth Edition, House of Culture for Publishing and Distribution, Jordan, p. 134.
} 
because, according to the old law, the judgment in such cases was considered not subject to appeal, while the Jordanian legislator deleted the fifth paragraph of the amended article which was stating that the judgment rendered in such cases is not subject to appeal in all cases, this is considered to be contrary to the Jordanian constitution, which is a citizen's prerogative which allows for the right to litigation, and that the courts of all degrees are open to citizens. Moreover, this text constitutes the manipulation and dominance of the judicial authority and some may resort to the use of such powers for retaliation, and other methods that may be addressed by members of the judicial control, since such decisions are not subject to judicial review and cannot be challenged.

It is also used in the amendment to the provisions of the paragraphs in Article (31) of the Jordanian Law of Trials, is to reduce the length of time in the proceedings of the litigation, where the amendment forces the officers of the control to expedite the presence to the crime scene, as well as expedite the speeding of proceedings.

It is also learned that the harshness that was imposed on the citizens under the previous law was disposed of and away from them through the amendment provided by the legislator to these texts.

\section{Conclusion}

The Jordanian legislator, who approaches the Iraqi legislator and other legislators, did well in the amendment to article 31 of the Jordanian Partial Jurisdiction Law.

In which the amendment contained in the article prohibits the arbitrary and arbitrary detention of members of the judicial police until the persons are referred to the judiciary.

This amendment came through the compatibility of the new text of what was guaranteed by the Jordanian Constitution in the texts of articles that talked about the rights of individuals, whether in inspection or arrest and other cases that was through the old text gives some powers to the members of the judicial control of the hegemony and the conduct of a violation of the Constitution under the Laws.

One of the ways in which the Jordanian legislator seeks to reach the truth and apply the law in the shortest period of time is through the cancellation of some of the powers that were exploited by the police officers and is considered a kind of prolongation of epilepsy.

\section{References}

Al-Hadithi, F. A. R. (2011). Explanation of the Code of Criminal Procedure (1st ed.). Dar Al Thaqafa for Publishing and Distribution, Amman, Jordan.

Al-Haiti, B. M. A.-M. (2010/2011). The suspicious crime and the effects of the expansion of the judicial control authority comparative study of Jordanian and Iraqi, published in Middle East University.

Al-Jabour, M. O. (1986). Jurisdiction of the Disciplinary Officer is a Comparative Study (1st ed.). Arabic House of Encyclopedias.

Bahar, M. K. (1998). Principles of Jordanian Criminal Procedure Law. House of Culture for Publishing and Distribution.

Najem, M. S. (2016). The brief in the Code of Criminal Procedure (3rd ed.). House of Culture for Publishing and Distribution.

Namour, M. S. (2016). Principles of Criminal Procedures Explanation of the Code of Criminal Procedure (4th ed.). House of Culture for Publishing and Distribution, Amman, Jordan.

\section{Copyrights}

Copyright for this article is retained by the author(s), with first publication rights granted to the journal.

This is an open-access article distributed under the terms and conditions of the Creative Commons Attribution license (http://creativecommons.org/licenses/by/4.0/). 